\title{
OPEN Wettability and sound absorption of graphene oxide doped polymer hydrogel
}

\author{
A. Khosrozadeh, R. Rasuli ${ }^{\bowtie}$, H. Hamzeloopak \& Y. Abedini
}

In this paper, we introduce a nanocomposite as a humidity-sensitive sound absorber. The nanocomposites were prepared using hydrogel polymer (HP) as a matrix and graphene oxide (GO) as a filler. Results show that the surface energy of the nanocomposite is $58.4 \mathrm{~mJ} \mathrm{~m}^{-2}$, and GO sheets increase the nanocomposite porosity from $2.6716 \mathrm{~cm}^{2} \mathrm{~g}^{-1}$ (for HP) up to $3.246 \mathrm{~cm}^{2} \mathrm{~g}^{-1}$. In addition, the diameter of nanocomposite pores is $8.5202 \mathrm{~nm}$ lower than that of HP $(\mathbf{1 0 . 2 7 4} \mathrm{nm})$. To study the effect of humidity on the sound absorption, we exposed them to moisture for 30 and 60 min and then measured sound absorption. Results show an absorption peak for the HP at $1022 \mathrm{~Hz}$ with an attenuation value of $30 \%$, while the nanocomposite shows two main peaks around 1898 and $3300 \mathrm{~Hz}$. In addition, results show that sound absorption peaks shift to higher frequencies according to humidification time.

Sound absorbers have attracted remarkable attention in recent years due to their promising application in industry and life $\mathrm{f}^{1-3}$. Sound-based devices can be divided into two categories with amorphous and crystal structures ${ }^{4,5}$. Phonon crystals have been widely studied to fabricate sound-based devices ${ }^{6}$. For instance, Xue-Feng et al. designed and simulated acoustic crystals to transfer the sound in one direction. Such a system is made from square steel blocks and can control the frequency of transmitted sound by mechanical rotation of the blocks ${ }^{7}$. In addition, by creating defects in a two-dimensional cylindrical grid immersed in water, one can conduct the sound waves and control their frequency ${ }^{8}$. In addition, topological acoustic insulators are interesting due to their applications as sound absorbers ${ }^{9,10}$.

Among various sound absorber materials, nanocomposites are promising for sound-based devices ${ }^{11}$. Typically, porous materials are applied as a sound absorber, and many studies have been performed to understand the absorption mechanism of these materials ${ }^{12}$. The propagation of sound is affected by environmental conditions, and sound absorption is dependent on ambient humidity and temperature ${ }^{13,14}$.

The low-cost and biocompatibility of hydrogel polymers introduce them as a promising candidate for sound absorbing in the transportation and construction industries ${ }^{15}$. Hydrogels are hydrophilic polymer with crosslinking and swollen ability, which retains large amounts of water. The moisture absorption of hydrogels by hydrophilic functional groups and their dissolution resistance are desirable to fabricate efficient sound absorbers ${ }^{16}$. The swelling behavior has a significant effect on the physical and mechanical properties of the final hydrogel, and environmental humidity and temperature affect the hydrogel-based sound absorber. Adding GO to the HP can improve its mechanical, thermal, hydrophilicity, and swelling properties. In addition, the properties of HP can be improved by varying concentrations of cross-linking agents in nano-composites ${ }^{11,12}$. Surrounding the reinforcing phase by hydrogel can improve sound absorption and increase the dissipation coefficient ${ }^{6,11}$. The size of the pores in a sound absorber determines the frequency of sound absorption ${ }^{17-19}$. Controlling the sound in resonant cavities, acoustic diodes, thermoelectric is the subject of recent researches ${ }^{20,21}$, and sound waves can be controlled by phonon crystals ${ }^{20}$. To achieve an impedance-tunable sound absorber, one should make it sensitive to the external actuator. Synthesizing low-cost and efficient tunable sound absorbers is a challenge in acoustic science ${ }^{22,23}$. As reported, reinforcing phases such as $\mathrm{GO}$ can be used as a reinforcing phase of composite to fabricate an efficient electromagnetic and sound wave absorber ${ }^{11,24,25}$.

In this paper, we used HP as a base polymer to fabricate humidity-sensitive sound absorber coating. GO was used to modify its surface energy and sound absorption, and the sound absorption of the prepared samples was measured after exposure to moisture at different times. In addition, the sound absorption peak of HP shifts from $1022 \mathrm{~Hz}$ to 2000 and $3538 \mathrm{~Hz}$ after humidification, showing hydrogen bond formation due to absorbed moisture that reinforces the polymer. However, for HGO samples, the frequency of sound absorption peak is $1898 \mathrm{~Hz}$, which changes to higher values by humidification for 30 and $60 \mathrm{~min}$, respectively. This paper is organized as 


\begin{tabular}{|l|r|}
\hline Atmospheric pressure $(\mathrm{Pa})$ & 88,310 \\
\hline Temperature $\left({ }^{\circ} \mathrm{C}\right)$ & 27 \\
\hline Humidity $(\%)$ & 38 \\
\hline Sound speed $\left(\mathrm{m} \mathrm{s}^{-1}\right)$ & 347 \\
\hline Air density $\left(\mathrm{kg} \mathrm{m}^{-2}\right)$ & 1 \\
\hline
\end{tabular}

Table 1. Environmental conditions for measuring sound absorption.
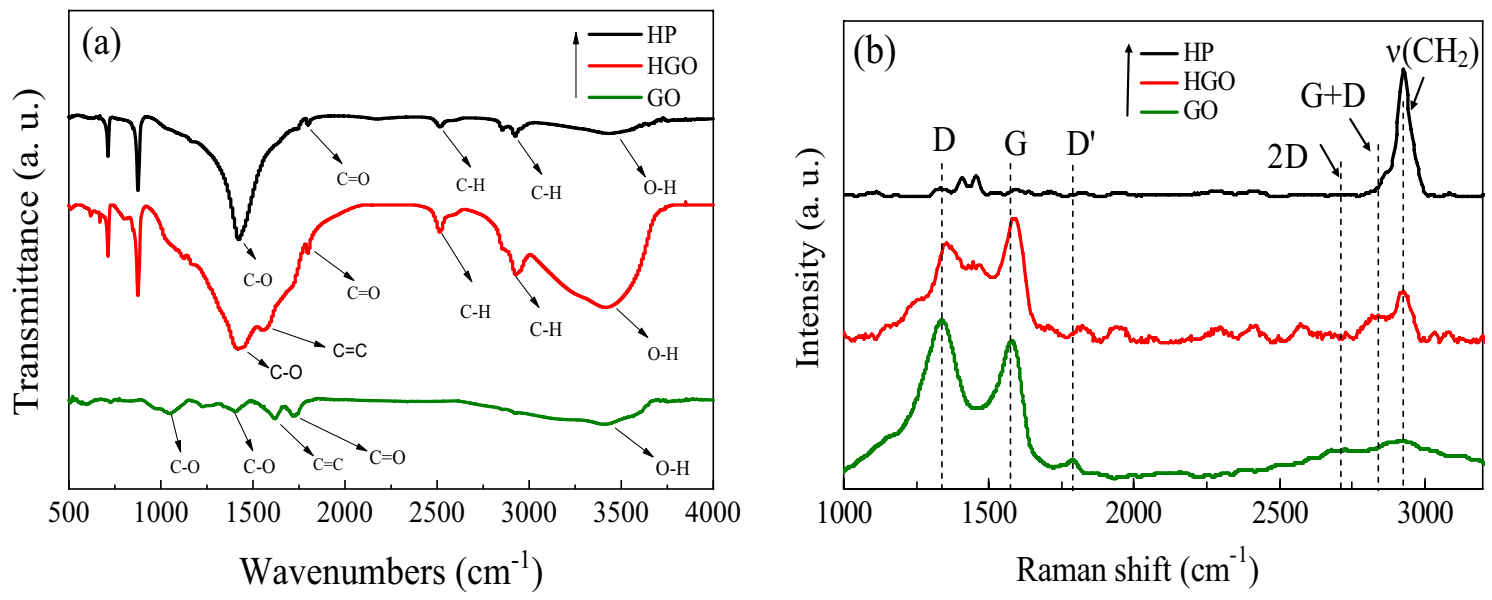

Figure 1. (a) Raman and (b) FTIR spectrum of GO, HP, and HGO.

follows: in the materials and method section, we present the composite preparation and characterization methods. In the results and discussion section, we discuss the prepared sample composition and porosity. Finally, we present sound absorption results and discuss the effect of humidity on sound absorption of the prepared samples.

\section{Materials and methods}

GO synthesis. GO was synthesized using the improved hummers method as reported previously by us ${ }^{11,26}$. In a typical method, we dissolved $0.1 \mathrm{~g}$ of graphite with $15 \mathrm{ml}$ of sulfuric acid (98\%) and then stirred for $15 \mathrm{~min}$ at $25^{\circ} \mathrm{C}$. Afterward, we added $0.3 \mathrm{~g}$ of $\mathrm{KMnO}_{4}$ to the solution and placed it in a water/ice bath for $5 \mathrm{~min}$. Afterward, $\mathrm{KMnO}_{4}$ was removed by $\mathrm{H}_{2} \mathrm{O}_{2}$ at $40{ }^{\circ} \mathrm{C}$, and then graphite oxide was exfoliated by ultra-sonication. Finally, the solution was placed in a centrifuge with a speed of 1200 RPM to separate GO from graphite oxide, as reported previously by us ${ }^{11}$.

Composite synthesis. First, we milled the $500 \mathrm{~g}$ of potassium polyacrylate (from Atieh Energy Company) for $60 \mathrm{~min}$ to obtain a powder. The resulting powder dissolved in $100 \mathrm{ml}$ of deionized water and then stirred for $30 \mathrm{~min}$ at $35^{\circ} \mathrm{C}$. Afterward, we added $5 \mathrm{ml}$ of hydrochloric acid (37\%) with $100 \mathrm{ml}$ of deionized water to the resulting mixture. Finally, we dried the resulting solution in an oven at $70{ }^{\circ} \mathrm{C}$ for $12 \mathrm{~h}$. To dope the GO in $\mathrm{HP}$ toward obtaining the most humidity-sensitive sample, we added $20 \mathrm{ml}$ of GO solution with a concentration of $2 \mathrm{~g} \mathrm{l}^{-1}$ to the primary solution and then dispersed it for $30 \mathrm{~min}$ by sonication. The prepared polymers for measuring the sound absorption were made using a laser cutting machine of $3 \mathrm{~cm}$ in diameter and $1 \mathrm{~cm}$ in thickness. The sound absorption measurement conditions were performed according to Table 1.

Characterization. FTIR spectroscopy was performed by Thermo scientific model Nicolet iS10. Field emission scanning electron microscopy (FESEM) and X-ray diffraction spectroscopy (EDX) was done by MIRA3 from TSCAN Company. Brunauer Emmett Teller's (BET) experiment was performed using a Belsorp mini II from Microtrac Bel Corp. The weight of HGO for BET analysis was 0.0586 and $0.0547 \mathrm{~g}$. Impedance Tube was utilized from Manufacturer of BSWA Technology Company Model: BSWA, SW477 + SW422. Raman spectroscopy was performed using Handheld Raman Analyzer (Firstguard) from Rigaku by an exciting wavelength of $1064 \mathrm{~nm}$. Thermogravimetric analysis (TGA) was done by TGA-DTA (Q600) from TA Company, and Transmission Electron Microscopy (TEM) images were recorded by Philips EM208S $100 \mathrm{kV}$.

\section{Results and discussions}

Composite characterization. FTIR is a powerful method to determine functional groups of the prepared nanocomposite ${ }^{27}$. Figure la shows the FTIR spectra for GO, HP, and an HGO. In a typical FTIR spectrum for $\mathrm{GO}$, the peaks at 3405,1622 , and $1732 \mathrm{~cm}^{-1}$ are attributed to $\mathrm{O}-\mathrm{H}, \mathrm{C}=\mathrm{O}$, and $\mathrm{C}=\mathrm{C}$ stretching modes. In addition, the peak observed at 1053 , and $1395 \mathrm{~cm}^{-1}$ are attributed to the $\mathrm{C}-\mathrm{O}$ stretching and bending modes. The peak at 

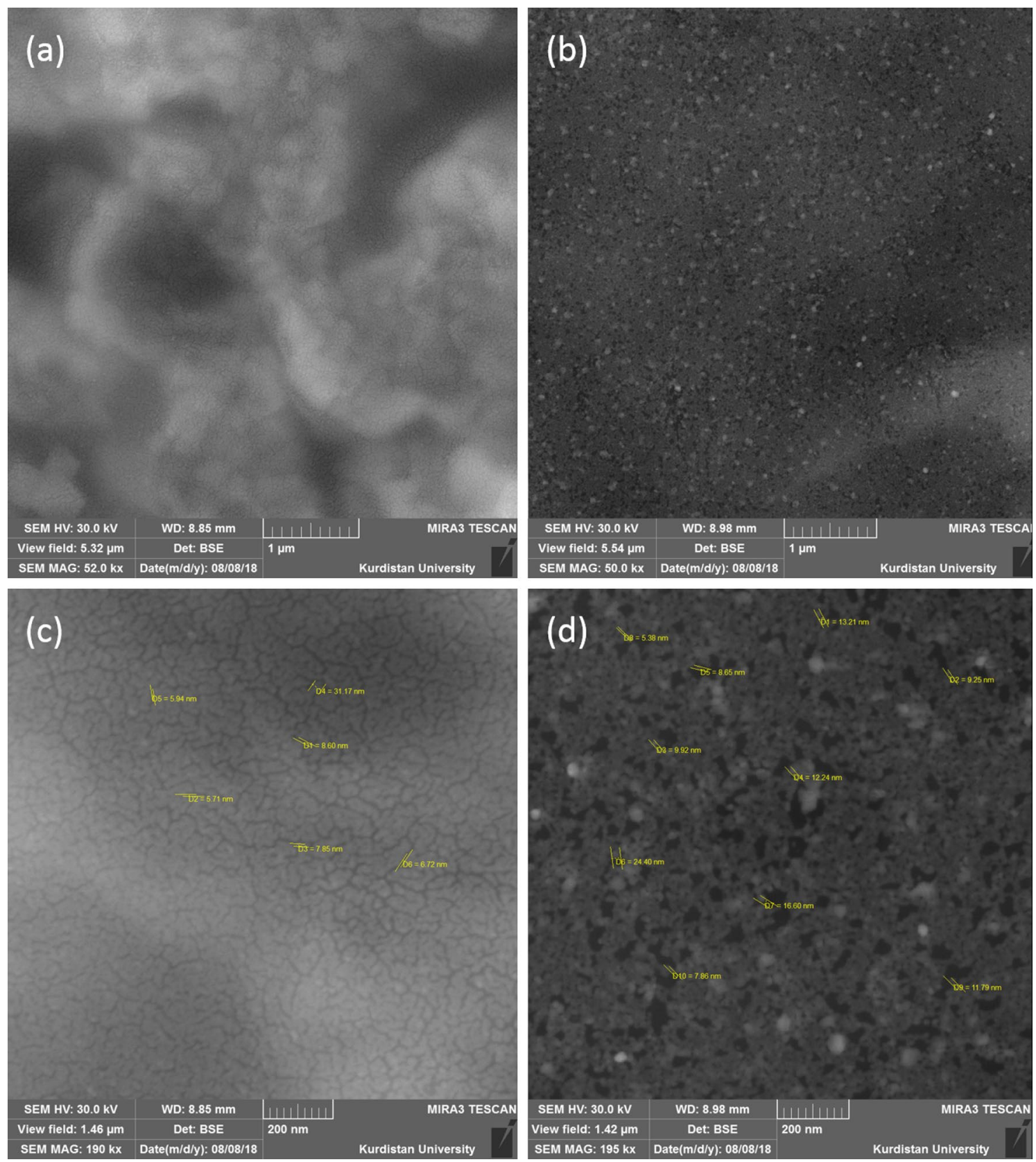

Figure 2. FESEM image of HP and HGO at the scale of $1 \mu \mathrm{m}$ and $200 \mathrm{~nm}$. (a), and (c) show HP surface; (b) and (d) exhibit HGO surface.

$2923 \mathrm{~cm}^{-1}$ is related to the $\mathrm{C}-\mathrm{H}$, and two peaks at 1799 and $2315 \mathrm{~cm}^{-1}$ are attributed to $\mathrm{C}=\mathrm{O}$ and $\mathrm{C}-\mathrm{O}$, respectively. $\mathrm{O}-\mathrm{H}$ peak also appeared at $~ 3500 \mathrm{~cm}^{-1}$ with a relative intensity of 2.1 compared to $\mathrm{C}=\mathrm{C}$ in agreement with previous reports ${ }^{11,28}$. As shown, the peak intensity of the $\mathrm{O}-\mathrm{H}$ functional group increases for HP due to GO in the HGO. This can be attributed to $\mathrm{O}-\mathrm{H}$ functional groups in $\mathrm{GO}$ and adsorbed moisture. In addition, there is an extra peak in the HGO spectrum at $1622 \mathrm{~cm}^{-1}$, corresponding to the $\mathrm{C}=\mathrm{C}$ bond in $\mathrm{GO}$. As shown, there is no considerable change in the spectrum after reinforcing the polymer by GO.

Raman spectroscopy was utilized to examine the GO sheets in the HGO. Carbonic materials show G and D peaks typically at $\sim 1580$ and $\sim 1350 \mathrm{~cm}^{-1}$, respectively ${ }^{29,30}$. The $\mathrm{G}$ band is attributed to $\mathrm{E}_{2 \mathrm{~g}}$ phonon, and the $\mathrm{D}$ peak is due to a breathing mode of $\kappa$-point phonons with $\mathrm{A}_{\mathrm{lg}}$ symmetry. The $\mathrm{D}$ band exhibits local defects of graphene oxide and graphite platelets. Raman spectra of the GO, HP, and HGO are presented in Fig. 1b. As shown, the $\mathrm{G}$ and D peaks for HGO respectively are seen at $\sim 1603$ and $\sim 1372 \mathrm{~cm}^{-1}$, while these are disappeared in the HP spectrum. The $\mathrm{G}$ (at $\sim 1582$ ) and $2 \mathrm{D}$ peaks $\left(\right.$ at $\sim 2680 \mathrm{~cm}^{-1}$ ) are also used to determine the layer number of GO and graphene $\mathrm{e}^{31-33}$. As shown in Fig. 1b, the $2 \mathrm{D}$ band of GO at $2681 \mathrm{~cm}^{-1}$ overlaps with the G $+\mathrm{D}$ band at $\sim 2850$ and $3000 \mathrm{~cm}^{-1}$ showing the existence of single and few-layer graphene ${ }^{28}$.

The morphology of the prepared samples was investigated by FESEM. Figure 2 shows the porous surface of the prepared composite. In addition, there are some cracks on the surface of HP, while the surface of HGO has 

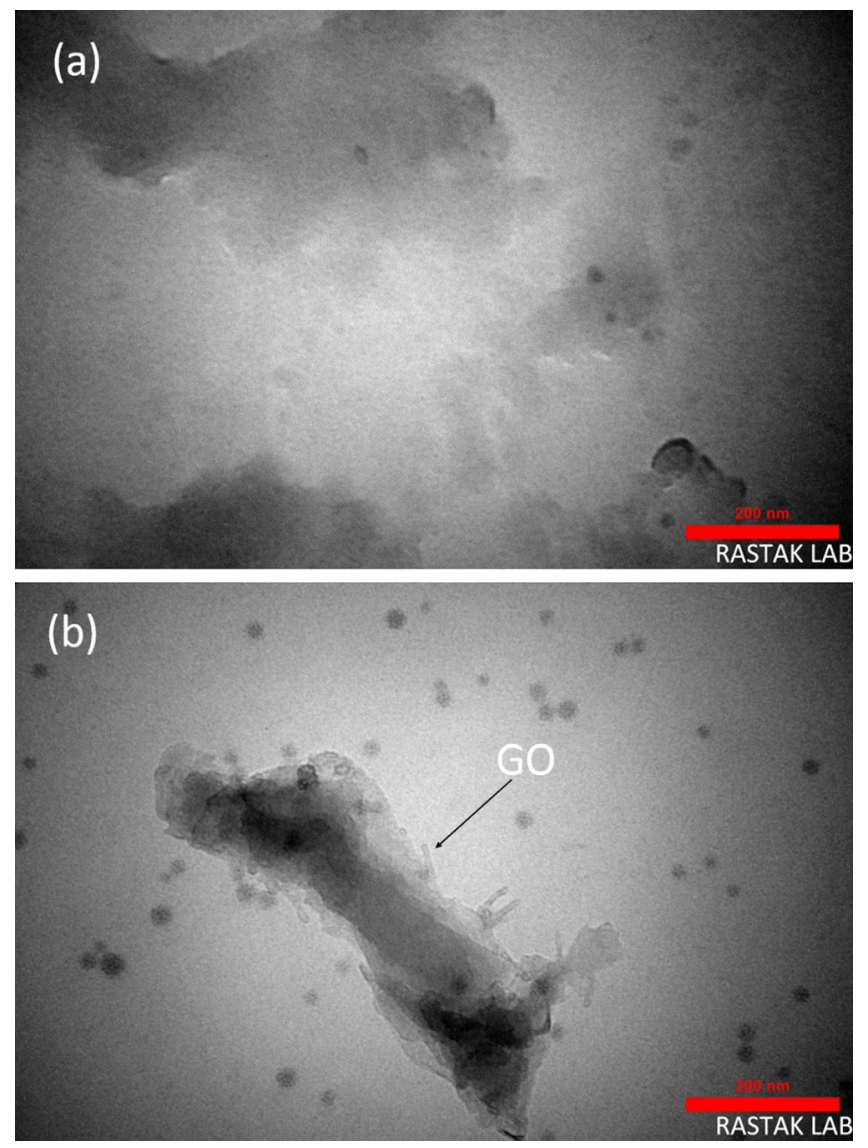

Figure 3. TEM image of (a) HP and (b) HGO with the scale bar of $200 \mathrm{~nm}$.
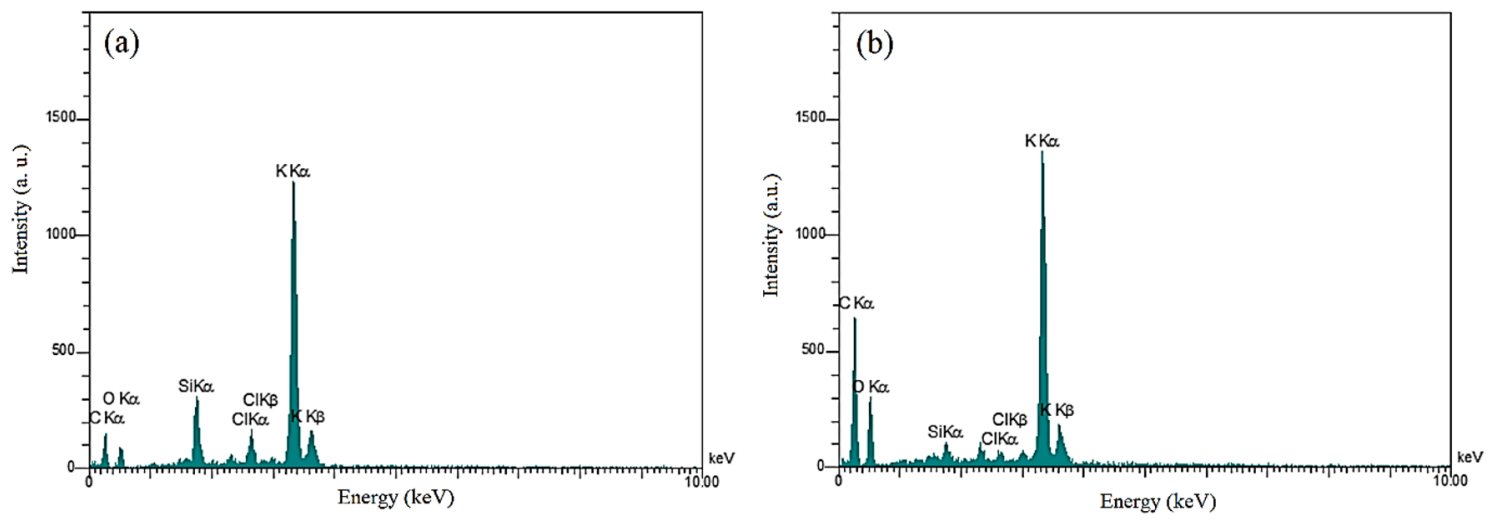

Figure 4. EDX Spectrum of (a) HP, and (b) HGO.

some micropores with a pore size of 5-16 nm. As shown, the porosity of the HGO seems more than the HP, which will be discussed later. In addition, the TEM image in Fig. 3 shows the presence of GO sheets inside HP and created pores in agreement with FESEM results.

To perform elemental analysis of the samples, we used the EDX experiment. The results of EDX are shown in Fig. 4 and Table 2. As shown in Fig. 4a, about $49.04 \%$ of HP is carbon with $15.55 \%$ oxygen. However, according to Fig. $4 \mathrm{~b}$ and Table 2 for the HGO, $65.98 \%$ of the composite is carbon, and $18.75 \%$ is oxygen. Results show that carbon and oxygen in HGO are more than HP due to GO, which agrees with FTIR results.

TGA residuum was used to quantify loaded species amount into the polymers. As shown in Fig. 5a, HP weight in TGA has two main steps. The first step (below $250^{\circ} \mathrm{C}$ ) is attributed to the moisture, and the second step (above $250^{\circ} \mathrm{C}$ ) is associated with the degradation of the hydrogels that can be several stages depending on the polymer structure. Similar behavior is observed for HGO, and as shown in Fig. 5, in the first step, moisture is released 


\begin{tabular}{|l|l|r|r|r|r|}
\hline \multirow{2}{*}{ Element } & \multirow{2}{*}{ Shell } & \multicolumn{2}{|l|}{ Weight\% } & \multicolumn{2}{l|}{ Atomic\% } \\
\cline { 3 - 7 } & HP & HGO & \multicolumn{1}{l|}{ HP } & HGO \\
\hline $\mathrm{C}$ & $\mathrm{K}$ & 27.12 & 47.08 & 49.04 & 65.98 \\
\hline $\mathrm{O}$ & $\mathrm{K}$ & 11.46 & 17.82 & 15.55 & 18.75 \\
\hline $\mathrm{Si}$ & $\mathrm{K}$ & 4.95 & 0.73 & 3.83 & 0.44 \\
\hline $\mathrm{Cl}$ & $\mathrm{K}$ & 4.01 & 0.78 & 2.45 & 0.37 \\
\hline $\mathrm{K}$ & $\mathrm{K}$ & 52.46 & 33.60 & 29.13 & 14.46 \\
\hline
\end{tabular}

Table 2. Quantitative results obtained from the EDX spectrum of HP and HGO.
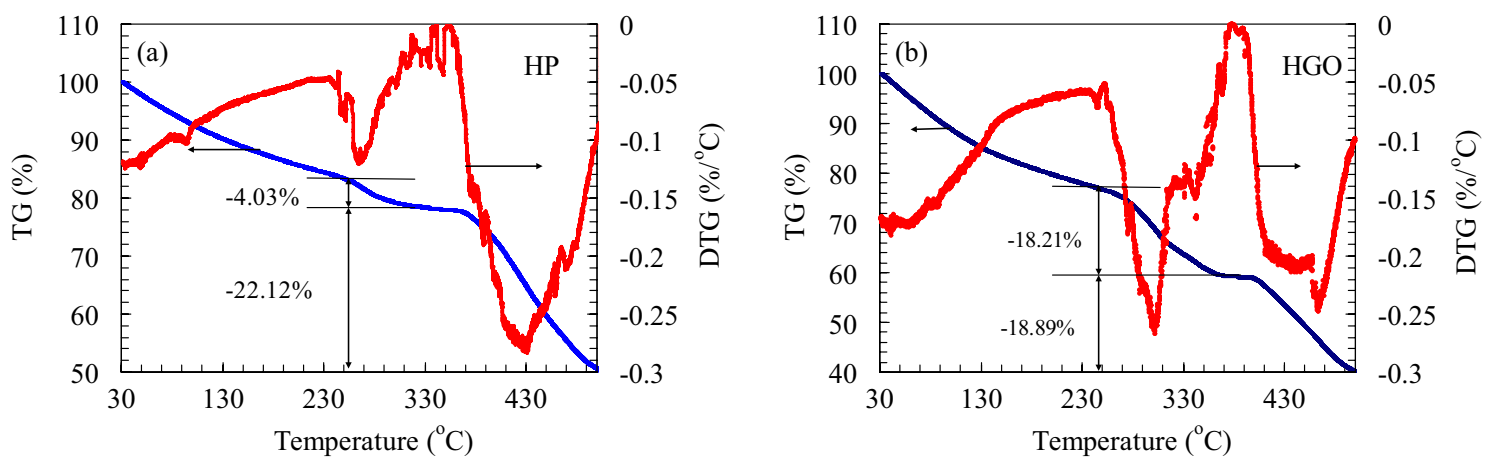

Figure 5. TGA and DTG for (a) HP and (b) HGO.

slowly at $230-310^{\circ} \mathrm{C}$ with a maximum release rate at $305^{\circ} \mathrm{C}$ (Fig. 5b). The different release kinetics of $\mathrm{HP}$ and HGO is due to the different interactions between the water molecules in HP and HGO.

Another factor in sound absorption is the porosity of sound absorbers ${ }^{12}$. Polymer surface area was investigated using BET analysis from $\mathrm{N}_{2}$ adsorption-desorption isotherms, and results show $3.2416 \mathrm{~m}^{2} \mathrm{~g}^{-1}$ and $2.6716 \mathrm{~m}^{2} \mathrm{~g}^{-1}$ specific surface areas for HGO and HP, respectively. In addition, the average diameter of the pores in the HP is $10.274 \mathrm{~nm}$, while this is $8.520 \mathrm{~nm}$ for HGO. The BET experiment was performed by the adsorption and desorption of nitrogen isomers at $77 \mathrm{~K}$. According to BET theory, the gas adoption can be done in multi-layered form, without any reaction with adjacent molecules ${ }^{34}$. Typically the increasing trend at low pressure shows micropores, and the hysteresis loop at high pressure is attributed to meso/macropores. As shown in Fig. 6, the absorption and desorption graph of the HP shows type III isotherm indicating weak interaction in the first layer between absorbent and absorber ${ }^{34}$. However, as presented in Table 3, the HGO shows more porosity than the HP, while pore size calculations by the $\mathrm{BJH}$ model based on the Kelvin equation give a value of $2.58 \mathrm{~nm}$ for both samples ${ }^{35,36}$. It is known that BET calculation measures the surface areas, and results can be larger according to enhanced interactions of the gas inside the pores ${ }^{37}$. However, the $\mathrm{BJH}$ model gives the pore radius from adsorbed/desorbed volume at a given pressure according to the following formula ${ }^{38}$ :

$$
\ln \left(p / p_{0}\right)=-2 \gamma M / R \operatorname{Tr}_{k},
$$

where $\gamma$ and $M$ are the surface tension of gas and the molar volume of the adsorbate, respectively. In this model, cylindrical pores are considered, and the Kelvin radius $\left(r_{k}\right)$ is taken equal to the mesopores radius minus the thickness of the adsorbed film. Since the pores in TEM and FESEM images are not cylindrical therefore one gets a smaller pore size than the mean pore size from the BET model.

The contact angle of water droplets was measured on the surface of the HP and HGO. We recorded the contact angle of the droplet for at least 10 points on the surface, immediately and after $20 \mathrm{~s}$. The mean contact angle of the water droplets on the HP and HGO surface is $52.4^{\circ}$ and $40.9^{\circ}$ at first, respectively (Fig. $\left.7 \mathrm{a}, \mathrm{b}\right)$. Using the Neumann method, we obtained the surface energy by the following formula:

$$
\ln \left[\gamma_{l}\left(\frac{(\cos \theta+1)}{2}\right)^{2}\right]=\ln \left(\gamma_{l}\right)-\beta\left(\gamma_{s}-\gamma_{l}\right)^{2} .
$$

In Eq. (2), $\gamma_{l}, \gamma_{s}$, and $\theta$ represent the surface tension of the liquid, sample, and the contact angle of a droplet, respectively. To obtain the surface energy, we measured the contact angle of various liquids (including ethylene glycol, water, acetone, DMF, and $\mathrm{H}_{2} \mathrm{O}_{2}$ ) on the surface. Corresponding error bars in Fig. 7c were obtained by averaging the values at different points. By plotting $\ln \left[\gamma_{l}\left(\frac{(\cos \theta+1)}{2}\right)^{2}\right]$ versus $\gamma_{l}$ and fitting a second-order curve (Fig. 7c), $\beta$ is determined as $-0.0001 \mathrm{~m}^{4}(\mathrm{~mJ})^{-2}$, and surface energy of HP and HGO is calculated as 51.5 and $58.4 \mathrm{mJm}^{-2}$, respectively. Results confirm that the hydrophilicity of the HP increases due to GO in the polymer ${ }^{39}$. 

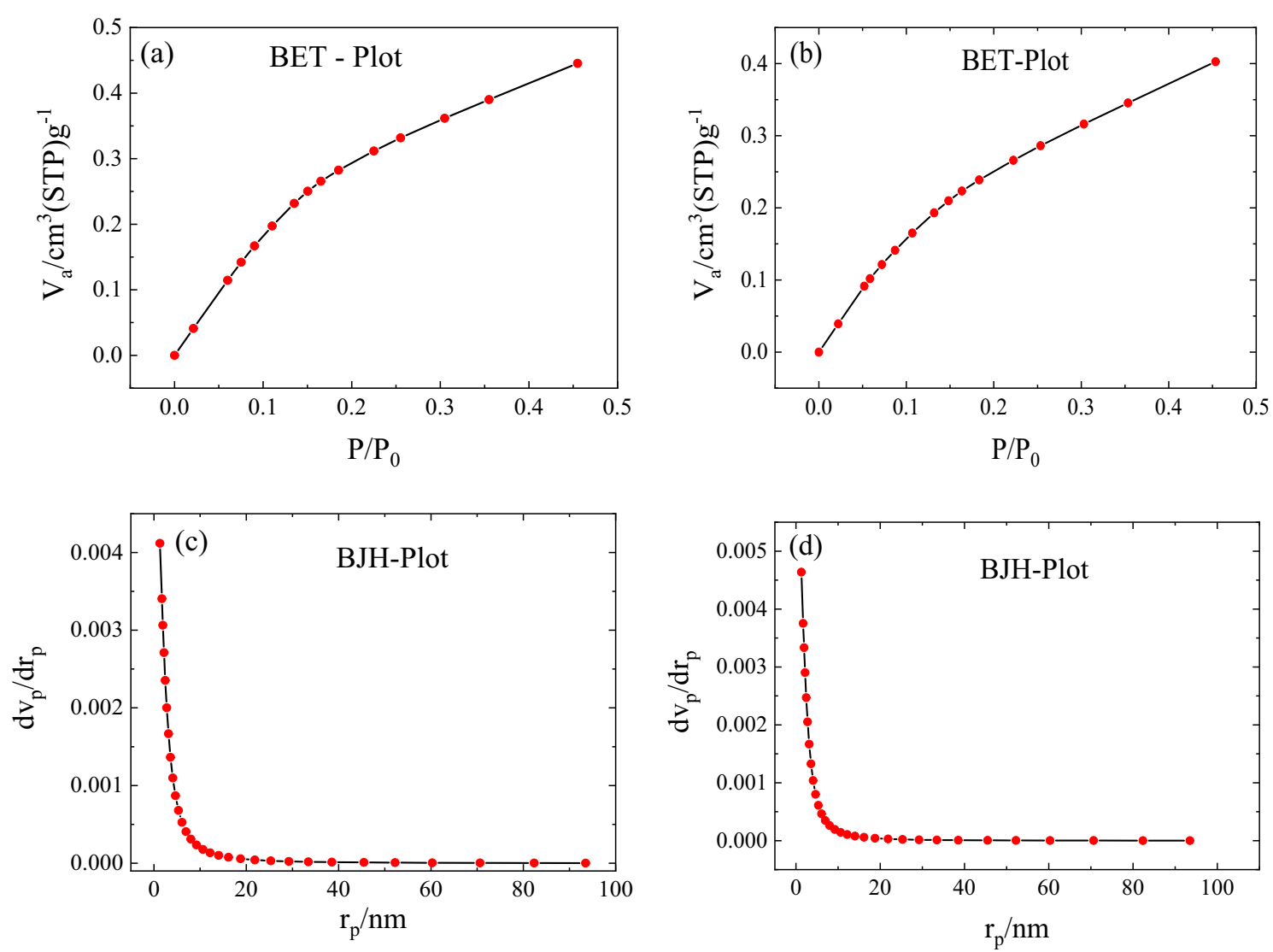

Figure 6. (a) and (b) show the BET plot of HP and HGO, and (c) and (d) present the BJH plot of HP and HGO, respectively. The corresponding data are presented in Table 3.

\begin{tabular}{|l|l|l|l|l|}
\hline \multirow{2}{*}{ Analysis } & Sample & Special surface area $\left(\mathbf{c m}^{\mathbf{2}} \mathbf{g}^{-1}\right)$ & Total volume of pore $\left(\mathbf{c m}^{2} \mathbf{g}^{-1}\right)$ & $\begin{array}{l}\text { Mean pore diameter }(\mathbf{B E T}) / \text { pore diameter } \\
(\mathbf{B J H})(\mathbf{n m})\end{array}$ \\
\hline \multirow{2}{*}{ BET } & HP & 2.672 & 0.00686 & 10.27 \\
\cline { 2 - 5 } & HGO & 3.242 & 0.00690 & 8.52 \\
\hline \multirow{2}{*}{ BJH } & HP & 8.299 & 0.00823 & 2.58 \\
\cline { 2 - 5 } & HGO & 8.939 & 0.00945 & 2.58 \\
\hline
\end{tabular}

Table 3. BET and BJH analysis details for HP and HGO.

Adding GO as a reinforcing phase increases the surface porosity that enhances the surface roughness, leading to the increase of surface hydrophilicity according to the well-known Wenzel model ${ }^{40}$.

Sound absorption. To measure the sound absorption, we used a two-microphone impedance tube with a diameter of $3 \mathrm{~cm}$ (BSWA model 422). The absorption coefficient, reflection, impedance, and sound admittance were measured by the impedance tube. Sound reflection measurement was carried out using the transfer function method, according to Eq. (2):

$$
r=r_{r}+i r_{i}=H_{12}+\frac{H_{I}}{H_{R}}-H_{12} e^{i 2 k x_{1}}
$$



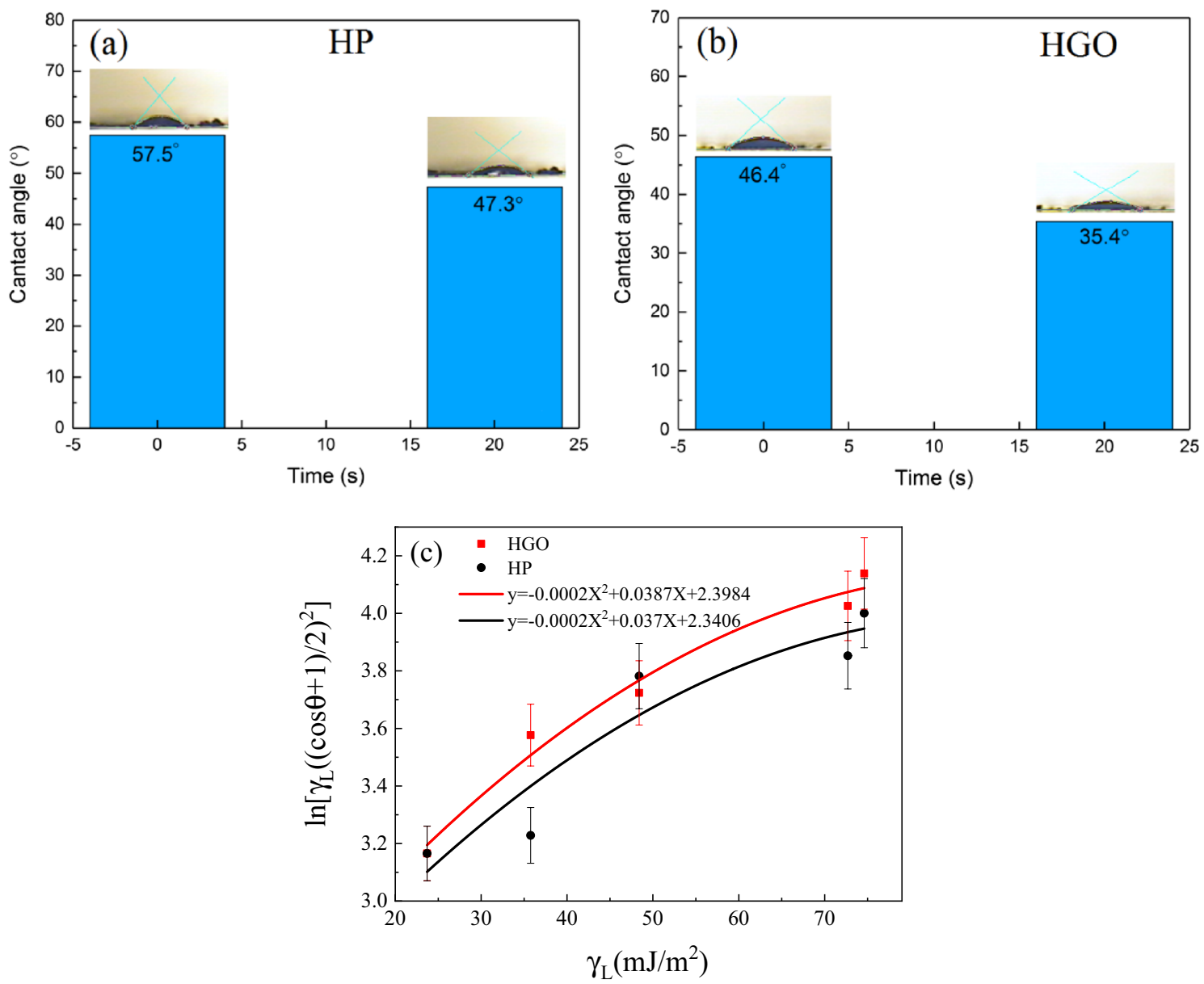

Figure 7. (a) and (b) the mean contact angle of water droplets on the HP and HGO immediately after dropping, and after $20 \mathrm{~s}$, (c) The fitted curve on contact angle results of various liquids to calculate the surface energy of $\mathrm{HP}$ and HGO.

where $r_{r}$ and $r_{i}$ are the real and imaginary components of the reflected wave, respectively. $x_{1}$ is the sample distance from the farther microphone. $\mathrm{H}_{\mathrm{I}}$ and $\mathrm{H}_{\mathrm{R}}$ are also the transfer function for the incident and reflected wave, and $\mathrm{H}_{12}$ is the transfer function between the two microphones. Finally, the absorption of sound was obtained from ${ }^{41}$ :

$$
\alpha=1-|r|^{2}=1-r_{r}^{2}-r_{i}^{2}
$$

To study the humidity effect on the sound absorption of the prepared samples, we exposed them to the humidity $(100 \% \mathrm{RH})$ for 30 and $60 \mathrm{~min}$. As shown in Fig. 8a, the main absorption peak appears at $1898 \mathrm{~Hz}$ with an absorption coefficient of 0.65 , while the second absorption peak is seen at a frequency of $3300 \mathrm{~Hz}$ with an absorption value of 0.25 . However, for the HP, we see an absorption peak at $1022 \mathrm{~Hz}$ with a value of 0.3 . The difference in the frequency of the absorption peak between HP and HGO can be attributed to the pores' diameter ${ }^{42}$. By exposing the HGO to the humidity for $30 \mathrm{~min}$, the peak shifts to the frequency of $2822 \mathrm{~Hz}$ with an absorption coefficient of 0.87 (Fig. 8b). However, for HP samples, the absorption peak appears at 2000 and $4906 \mathrm{~Hz}$ with absorption values of 0.88 and 0.62 , respectively. In addition, HGO and HP after 60 min humidity exposure show 

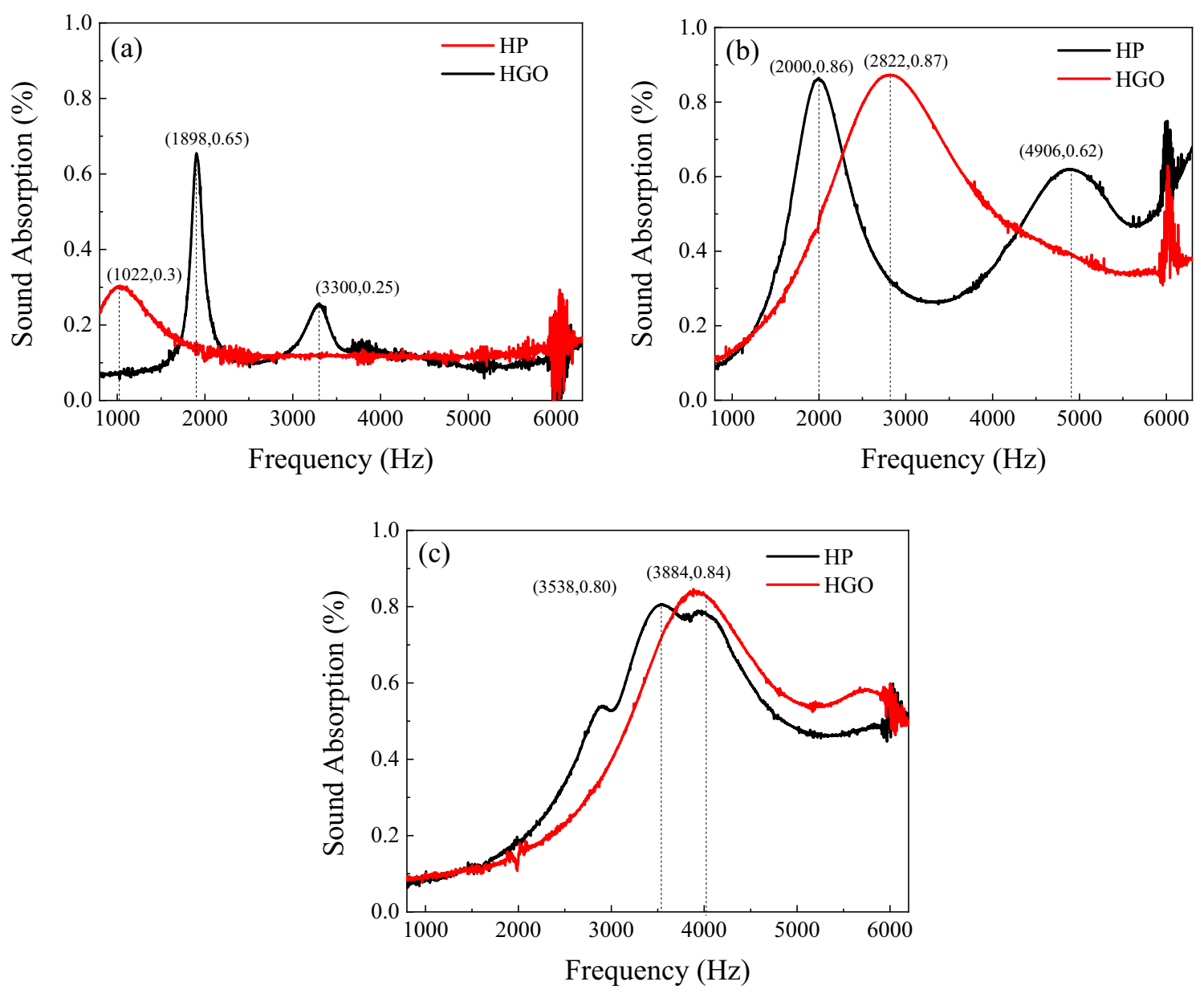

Figure 8. Sound absorption of (a) as-prepared, (b) after $30 \mathrm{~min}$ humidification, and (c) after $60 \mathrm{~min}$ humidification.

the peak at 3884 and $3538 \mathrm{~Hz}$, respectively (Fig. 8c). As a result, the frequency difference between HGO and bare $\mathrm{HP}$ decreases from 822 to $346 \mathrm{~Hz}$ by increasing the humidification time to $60 \mathrm{~min}$.

Results in Fig. 8 show an increase in sound absorption due to humidity. Sound absorbents can reduce sound energy by converting vibrating energy into heat ${ }^{43,44}$. As shown in Fig. 8, sound absorption in HGO is greater than HP, and the moisture increases the intensity of sound absorption peak for HGO with the values of 0.87 and 0.84. The humidification process is repeatable, and the prepared samples can be recovered by heating for $1 \mathrm{~h}$, while in the air atmosphere, it takes a month.

According to the Helmholtz theorem, in a resonance condition, the impedance becomes zero ${ }^{44}$. Figure 9a shows acoustic impedance for the HGO, which is zero in the range of $1500-2000 \mathrm{~Hz}$ and $3000-3500 \mathrm{~Hz}$. According to the Helmholtz plot, when the acoustic impedance is zero, resonance occurs in system ${ }^{11}$. Figure 9 a shows the maximum impedance domain in the frequency range of $2000-3000 \mathrm{~Hz}$ for HP and HGO, indicating the coating's resistance to sound waves. As shown in Fig. 9b, the acoustic impedance for HGO has the highest amplitude at the frequency range of 2500-3000 Hz. Figure 9c also shows that the acoustic impedance at 2500-4500 $\mathrm{Hz}$ for HGO has the highest amplitude. Acoustic impedance is the ratio of applied sound pressure to the speed of the matching particle ${ }^{11}$. Therefore, at such a frequency of sound, one sees maximum sound absorption of the prepared samples.

\section{Conclusions}

In summary, sound absorbers were prepared based on HP and GO, and then sound absorption was measured. We show that GO increases the surface energy of the nanocomposite as well as sound absorption. FESEM and BET results show a porous structure for HP while doping it by GO as the reinforcing phase increases porosity. The sound absorption was studied using an impedance tube in the frequency range of $1000-6000 \mathrm{~Hz}$. Results show that the HGO shows two main peaks around 1898 and $3300 \mathrm{~Hz}$, while HP exhibits one peak at $1022 \mathrm{~Hz}$. In addition, moisture exposure tunes the sound absorption, and two absorption peaks shift to 2000 and $4906 \mathrm{~Hz}$. 

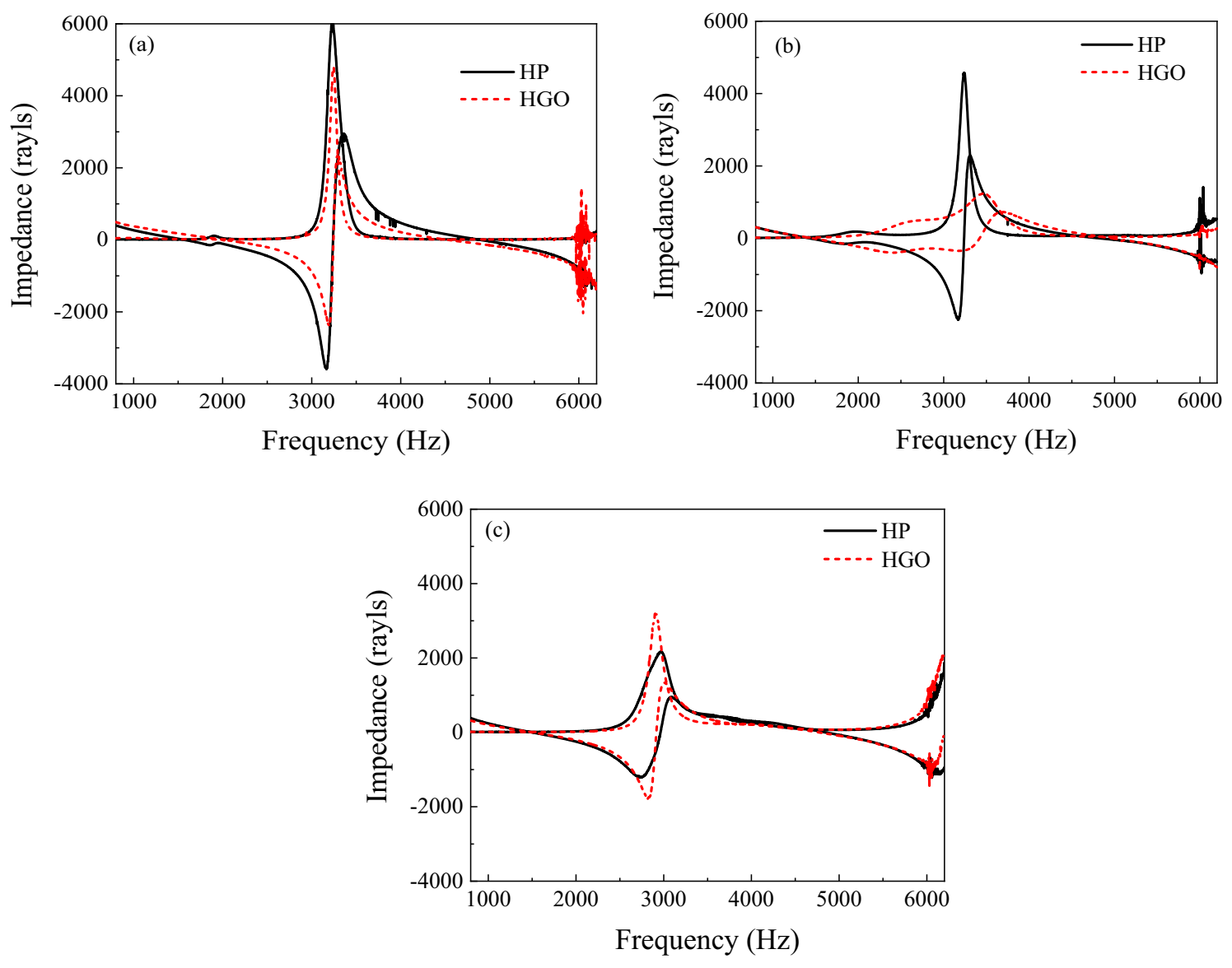

Figure 9. Acoustic impedance of HGO and HP after humidification for (a) 0, (b) 30, and (c) 60 min.

\section{Data availability}

The data presented in this study are available on request from the corresponding author.

Received: 2 April 2021; Accepted: 20 July 2021

Published online: 05 August 2021

\section{References}

1. Cheng, B., Gao, N., Zhang, R. \& Hou, H. Design and experimental investigation of broadband quasi-perfect composite loaded sound absorber at low frequencies. Appl. Acoust. 178, 108026 (2021).

2. Yu, T. et al. Acoustic insulation and absorption mechanism of metallic hollow spheres composites with different polymer matrix. Compos. Struct. 248, 112566 (2020).

3. Yang, X. et al. Multi-layer polymer-metal structures for acoustic impedance matching in high-frequency broadband ultrasonic transducers design. Appl. Acoust. 160, 107123. https://doi.org/10.1016/j.apacoust.2019.107123 (2020).

4. Balaji, P. S. \& Karthik SelvaKumar, K. Applications of nonlinearity in passive vibration control: A review. J. Vib. Eng. Technol. 9, 183-213. https://doi.org/10.1007/s42417-020-00216-3 (2021).

5. Vural, D. C. \& Leggett, A. J. Universal sound absorption in amorphous solids: A theory of elastically coupled generic blocks. J. Non-Cryst. Solids 357, 3528-3537. https://doi.org/10.1016/j.jnoncrysol.2011.06.035 (2011).

6. Lu, M.-H., Feng, L. \& Chen, Y.-F. Phononic crystals and acoustic metamaterials. Mater. Today 12, 34-42 (2009).

7. Li, X.-F. et al. Tunable unidirectional sound propagation through a sonic-crystal-based acoustic diode. Phys. Rev. Lett. 106, 084301 (2011).

8. Khelif, A. et al. Trapping and guiding of acoustic waves by defect modes in a full-band-gap ultrasonic crystal. Phys. Rev. B 68, 214301. https://doi.org/10.1103/PhysRevB.68.214301 (2003).

9. He, C. et al. Acoustic topological insulator and robust one-way sound transport. Nat. Phys. 12, 1124 (2016).

10. He, H. et al. Topological negative refraction of surface acoustic waves in a Weyl phononic crystal. Nature 560, 61 (2018).

11. Qamoshi, K. \& Rasuli, R. Subwavelength structure for sound absorption from graphene oxide-doped polyvinylpyrrolidone nanofibers. Appl. Phys. A 122, 788 (2016).

12. Shen, Y. \& Jiang, G. The influence of production parameters on sound absorption of activated carbon fiber felts. J. Text. Inst. 107, 1144-1149 (2016).

13. Otsuru, T., Tomiku, R., Okamoto, N. \& Yamauchi, S. Sound absorption deviation measured using pressure-velocity sensors by ensemble averaging technique under different relative humidity conditions. Appl. Acoust. 122, 121-127 (2017).

14. Yilmazer, S. \& Ozdeniz, M. B. The effect of moisture content on sound absorption of expanded perlite plates. Build. Environ. 40, 311-318 (2005).

15. Sun, X., Agate, S., Salem, K. S., Lucia, L. \& Pal, L. Hydrogel-based sensor networks: Compositions, properties, and applications-A review. ACS Appl. Bio Mater. 4, 140-162 (2020). 
16. Thompson, B. R. et al. Sound transmission loss of hierarchically porous composites produced by hydrogel templating and viscous trapping techniques. Mater. Chem. Front. 1, 2627-2637. https://doi.org/10.1039/C7QM00371D (2017).

17. Gao, N., Wu, J., Lu, K. \& Zhong, H. Hybrid composite meta-porous structure for improving and broadening sound absorption. Mech. Syst. Signal Process. 154, 107504 (2021).

18. Opiela, K. C. \& Zieliński, T. G. Microstructural design, manufacturing and dual-scale modelling of an adaptable porous composite sound absorber. Compos. Part B Eng. 187, 107833 (2020).

19. Xie, S., Yang, S., Yang, C. \& Wang, D. Sound absorption performance of a filled honeycomb composite structure. Appl. Acoust. 162, $107202(2020)$.

20. Zhu, J., Zhu, X., Yin, X., Wang, Y. \& Zhang, X. Unidirectional extraordinary sound transmission with mode-selective resonant materials. Phys. Rev. Appl. 13, 041001 (2020).

21. Liu, J., Guo, H. \& Wang, T. A review of acoustic metamaterials and phononic crystals. Curr. Comput.-Aided Drug Des. 10, 305 (2020).

22. Thomazelli, R. \& Bertoli, S. An experimental study on the optimization of the production and efficiency of tunable Helmholtz absorbers for the modal control of small rooms. Build. Acoust. 26, 69-91. https://doi.org/10.1177/1351010X19829870 (2019).

23. Li, Y. et al. Superbroad-band actively tunable acoustic metamaterials driven from poly (ethylene terephthalate)/Carbon nanotube nanocomposite membranes. Nano Res. 14, 100-107 (2021).

24. Liu, P. et al. Synthesis of lightweight N-doped graphene foams with open reticular structure for high-efficiency electromagnetic wave absorption. Chem. Eng. J. 368, 285-298 (2019).

25. Wang, Y., Di, X., Wu, X. \& Li, X. MOF-derived nanoporous carbon/Co/ $/ \mathrm{Co}_{3} \mathrm{O}_{4} / \mathrm{CNTs} / \mathrm{RGO}$ composite with hierarchical structure as a high-efficiency electromagnetic wave absorber. J. Alloy. Compd. 846, 156215. https://doi.org/10.1016/j.jallcom.2020.156215 (2020).

26. Shahriary, L. \& Athawale, A. A. Graphene oxide synthesized by using modified hummers approach. Int. J. Renew. Energy Environ. Eng. 2, 58-63 (2014).

27. Ingle Jr, J. D. \& Crouch, S. R. Spectrochemical analysis. (1988).

28. Rasuli, R., Mokarian, Z., Karimi, R., Shabanzadeh, H. \& Abedini, Y. Wettability modification of graphene oxide by removal of carboxyl functional groups using non-thermal effects of microwave. Thin Solid Films 589, 364-368. https://doi.org/10.1016/j.tsf. 2015.06.002 (2015).

29. Akhavan, O. The effect of heat treatment on formation of graphene thin films from graphene oxide nanosheets. Carbon 48, 509-519 (2009).

30. Akhavan, O. Bacteriorhodopsin as a superior substitute for hydrazine in chemical reduction of single-layer graphene oxide sheets. Carbon 81, 158-166. https://doi.org/10.1016/j.carbon.2014.09.044 (2015).

31. Gao, L. et al. Repeated growth and bubbling transfer of graphene with millimetre-size single-crystal grains using platinum. Nat. Commun. 3, 699 (2012).

32. Chae, S. J. et al. Synthesis of large-area graphene layers on poly-nickel substrate by chemical vapor deposition: Wrinkle formation. Adv. Mater. 21, 2328-2333. https://doi.org/10.1002/adma.200803016 (2009).

33. Calizo, I., Balandin, A. A., Bao, W., Miao, F. \& Lau, C. N. Temperature dependence of the Raman spectra of graphene and graphene multilayers. Nano Lett. 7, 2645-2649. https://doi.org/10.1021/nl071033g (2007).

34. Chen, W., Li, F., Yu, J. \& Liu, L. A facile and novel route to high surface area ceria-based nanopowders by salt-assisted solution combustion synthesis. Mater. Sci. Eng. B 133, 151-156 (2006).

35. Liu, P. et al. Hollow engineering to Co@N-doped carbon nanocages via synergistic protecting-etching strategy for ultrahigh microwave absorption. Adv. Funct. Mater. 1, 10. https://doi.org/10.1002/adfm.202102812 (2021).

36. Wang, Y., Di, X., Lu, Z. \& Wu, X. Rational construction of hierarchical Co@C@NPC nanocomposites derived from bimetallic hybrid ZIFs/biomass for boosting the microwave absorption. J. Colloid Interface Sci. 589, 462-471. https://doi.org/10.1016/j.jcis. 2021.01.013 (2021).

37. Barrett, E. P., Joyner, L. G. \& Halenda, P. P. The determination of pore volume and area distributions in porous substances. I. Computations from nitrogen isotherms. J. Am. Chem. Soc. 73, 373-380. https://doi.org/10.1021/ja01145a126 (1951).

38. Medeiros-Costa, I. C., Laroche, C., Pérez-Pellitero, J. \& Coasne, B. Characterization of hierarchical zeolites: Combining adsorption/ intrusion, electron microscopy, diffraction and spectroscopic techniques. Microporous Mesoporous Mater. 287, 167-176. https:// doi.org/10.1016/j.micromeso.2019.05.057 (2019).

39. D’urso, B., Simpson, J. \& Kalyanaraman, M. Emergence of superhydrophobic behavior on vertically aligned nanocone arrays. Appl. Phys. Lett. 90, 044102 (2007).

40. Allahyari, P., Rasuli, R., Servati, M. \& Alizadeh, M. Superhydrophobic and low-hysteresis coating based on rubber-modified $\mathrm{TiO}_{2} /$ $\mathrm{SiO}_{2}$ nanoparticles. Bull. Mater. Sci. 44, 85. https://doi.org/10.1007/s12034-021-02384-8 (2021).

41. Novak, C., Ule, H. \& Cert, J. K. I. B. In INTER-NOISE and NOISE-CON Congress and Conference Proceedings. 815-822 (Institute of Noise Control Engineering).

42. Maldovan, M. Sound and heat revolutions in phononics. Nature 503, 209 (2013).

43. Rabbi, A., Bahrambeygi, H., Nasouri, K., Shoushtari, A. M. \& Babaei, M. R. Manufacturing of PAN or PU nanofiber layers/PET nonwoven composite as highly effective sound absorbers. Adv. Polym. Technol. 33, 21425-21432 (2014).

44. Cox, T. \& d'Antonio, P. Acoustic Absorbers and Diffusers: Theory, Design and Application (CRC Press, 2016).

\section{Acknowledgements}

We thanks University of Zanjan for financial supports.

\section{Author contributions}

A.K., formal analysis investigation, writing-original draft preparation, writing-review and editing, R.R., conceptualization and supervision, methodology, writing-review and editing, H.H., writing-review, editing and Y.A., supervision. All authors have read and agreed to the published version of the manuscript.

\section{Competing interests}

The authors declare no competing interests.

\section{Additional information}

Correspondence and requests for materials should be addressed to R.R.

Reprints and permissions information is available at www.nature.com/reprints.

Publisher's note Springer Nature remains neutral with regard to jurisdictional claims in published maps and institutional affiliations. 
(c) (i) Open Access This article is licensed under a Creative Commons Attribution 4.0 International cc) License, which permits use, sharing, adaptation, distribution and reproduction in any medium or format, as long as you give appropriate credit to the original author(s) and the source, provide a link to the Creative Commons licence, and indicate if changes were made. The images or other third party material in this article are included in the article's Creative Commons licence, unless indicated otherwise in a credit line to the material. If material is not included in the article's Creative Commons licence and your intended use is not permitted by statutory regulation or exceeds the permitted use, you will need to obtain permission directly from the copyright holder. To view a copy of this licence, visit http://creativecommons.org/licenses/by/4.0/.

(C) The Author(s) 2021 